Anuario del Instituto de Historia Argentina, vol. 17, nº 1, e044, junio 2017.

ISSN 2314-257X

Universidad Nacional de La Plata.

Facultad de Humanidades y Ciencias de la Educación.

Centro de Historia Argentina y Americana

\title{
Campos, Esteban, Cristianismo y Revolución. El origen de Montoneros: violencia, política y religión en los 60, Ciudad Autónoma de Buenos Aires, Edhasa, 2016, 224 pp
}

\author{
Esteban Nicolás Barroso * \\ * Instituto de Investigaciones en Humanidades y Ciencias Sociales - Universidad Nacional \\ de La Plata, Argentina | esteban barroso@live.com.ar
}

Este libro es una versión concentrada de la tesis doctoral del autor, titulada "De las prácticas discursivas a las redes de comunicación. La construcción de una hegemonía alternativa en la revista Cristianismo y Revolución y la preparación espiritual para la lucha armada en la Argentina (1966-1971)”. Cristianismo y Revolución (C \& R) surgió en el año 1966, como un espacio plural de resistencia a la dictadura militar encabezada por Ongania. Dirigida por Juan García Elorrio y su compañera Casiana Ahumada, sus integrantes provenían del integrismo, el nacionalismo, y el humanismo católico. ¿Por qué Esteban Campos decidió analizar esta revista? En la sección final del libro, sostiene que dicha elección le permitió realizar un estudio de caso en el género de la historia política, pero también aproximarse de un modo más general al contexto de la segunda mitad de la década del sesenta. En otras palabras, su estudio acerca de C \& R se inscribe dentro de una problemática más amplia, la de las transformaciones en la identidad de los actores políticos y sociales en la década del sesenta.

Teniendo en mente este objetivo, el autor parte de la hipótesis de que "la convergencia de las identidades obrera, cristiana, guerrillera y peronista permitió la emergencia de un proyecto de hegemonía alternativa, visible en las páginas de C \& R a finales de la década de 1960” (p. 22). La atención, entonces, no está centrada ni en los orígenes de Montoneros, ni en el posible rol que puede haber tenido en ello C \& R. Por el contrario, lo que se busca es analizar, específicamente, cómo se organizaba el discurso interno de esta revista, así como su transformación a lo largo del tiempo, hasta tornarse visible en él la existencia de un proyecto de hegemonía alternativa.

Este concepto, por lo tanto, es central en su investigación. Escuetamente, Esteban Campos afirma que, según Raymond Williams, dicha hegemonía podría ser definida como la “conexión práctica de formas de lucha que 
implica la resistencia organizada de las clases subalternas, a través de la creación de formaciones culturales y políticas opuestas a la clase dominante” (p. 23). Para alcanzar sus objetivos, el autor se basa fundamentalmente en dos fuentes: la propia revista $\mathrm{C} \& \mathrm{R}$, y entrevistas realizadas a hombres y mujeres que formaron parte de la revista o que integraron su público lector original. Aquellas son abordadas a partir de las herramientas aportadas por el análisis del discurso, la teoría cultural de Raymond Williams, y la historia oral. Pequeños comentarios sobre ellas y sobre el motivo por el cual se decidió emplear el recurso de las entrevistas, aparecen dispersos en diversas notas a lo largo del libro.

Una de las puntualizaciones realizadas por el autor sobre la historia oral resulta esclarecedora. Afirma que la selección de esta metodología estuvo relacionada con la posibilidad de "advertir algunos fenómenos de recepción y circulación de las ideas, reconstruyendo el circuito que iba de los productores culturales a los lectores militantes” (p. 50). Esto, sumado a la decisión de entrevistar a personas que leían la revista sin ser parte de ella, se encuentra claramente vinculado con los objetivos de su investigación: el análisis de C \& R sirve para reconstruir el proceso de transformación de identidades políticas que se vivió en la década del sesenta, y, más específicamente, la conformación de un proyecto de hegemonía alternativa. Varias preguntas recorren, de esta manera, los diferentes capítulos de la obra: ¿surgió realmente tal proyecto? ¿Cómo se articuló y se hizo visible en C \& R? ¿Cuáles fueron sus principales rasgos?

Para ofrecer respuestas a dichos interrogantes, el autor divide su investigación en cuatro partes. En la primera de ellas (capítulos 1 y 2) analiza la manera en la que se abordó la problemática religiosa en la revista. La intención de García Elorrio era convencer a los cristianos de la necesidad de emplear la lucha armada para tomar el poder y abordar la construcción de una sociedad socialista. En varias ocasiones, Esteban Campos sostiene que, para el momento en el que la revista dejó de ser publicada, su misión estaba cumplida: varios de sus ex integrantes, iniciados en el activismo católico, ya formaban parte de organizaciones armadas. El proceso de radicalización ideológica que hizo posible que esta misión se cumpliera se dio en sucesivos momentos. Entre el 1965 y el 1967 se puede observar, paralelamente al diálogo entre cristianos y peronistas, una "traducción" de contenidos cristianos a seculares en diferentes artículos de la revista, con la intención de generar un nuevo lenguaje político. 1967 y 1968 fueron años marcados por el transito al cristianismo liberacionista, cuyo signo más evidente fue la inclusión de los tópicos de la revolución y de la historia en la cosmovisión del catolicismo renovador. Finalmente, en los años finales de la publicación aparece con fuerza una teología de la violencia. Ella sostenía, desde una ética cristiana, la necesidad de "encarnarse” en el pecado como lo hizo Jesucristo; descender a lo más bajo, a la violencia, para elevarse y salvar a los oprimidos. Todo esto, en opinión de Esteban Campos, implicaba romper con el monopolio ideológico que detentaba la jerarquía eclesiástica para representar la violencia empleada por las organizaciones armadas, contribuyendo de esta manera en la construcción de un proyecto de hegemonía alternativa.

La segunda parte (capítulo tres) busca analizar el rápido proceso de secularización que sufrió la caracterización de los trabajadores por parte de la revista. Es así que, durante los primeros años, resultaba usual que en el discurso de C \& R se asociara a la clase obrera con la pobreza, una visión claramente deudora de concepciones teológicas provenientes del catolicismo tradicional. Sin embargo, con el tiempo (y especialmente a partir del 1969) el obrero empezó a ser concebido explícitamente como proletario, adoptándose el discurso del peronismo revolucionario y el sindicalismo de liberación, y empleando al marxismo como método de análisis. Esto llevó a abordar una cuestión problemática: el rol que debían desempeñar los trabajadores y el peronismo en el proceso insurreccional que se vislumbraba. Según Esteban Campos, en la revista se concebía al peronismo como "la condición de posibilidad y al mismo tiempo un límite a superar del proyecto de hegemonía alternativa” ( p. 207). Aquel era el más alto grado de conciencia al que había llegado la clase trabajadora a través de su propia e intuitiva experiencia. Sin embargo, era necesario, en la opinión de esta publicación, dar un paso más, lo que suponía la construcción y consolidación 
de una vanguardia armada.

Precisamente, la tercera parte (capítulo cuatro) se centra específicamente en el tratamiento realizado por C \& $\mathrm{R}$ sobre las organizaciones armadas. Particularmente le interesa al autor resaltar las relaciones discursivas establecidas entre lo político y lo militar, afirmando que la figura de la guerra sirvió para establecer una cierta equivalencia entre ambos términos. La intención de esto fue "desplazar discursivamente el conflicto social hacia un enfrentamiento armado” (p. 208). Así, en varios artículos se hace referencia a la violencia revolucionaria como un fin en sí mismo, notándose a su vez un claro énfasis en las preocupaciones “técnicas" (el manejo de las armas, las normas de seguridad, etc.) por sobre las prioridades típicas de la izquierda tradicional. Esto está, según el autor, claramente vinculado con la construcción de una hegemonía alternativa, ya que la enunciación de una guerra revolucionaria era una condición necesaria para su surgimiento. Y sin embargo, rápidamente aparecieron tanto en las prácticas como en los discursos de las organizaciones armadas los primeros síntomas de una incipiente militarización, que con el correr del tiempo terminó perjudicando al propio proyecto de hegemonía alternativa que buscaban dirigir. Lentamente pasaron del terreno político al militar, y sus estructuras se demostraron ineficaces para afrontar con éxito el combate emprendido contra las Fuerzas Armadas.

Por último, en los capítulos que cierran su investigación, el autor analiza el problema del sujeto y de la vanguardia armada, así como la importancia adquirida por la figura de Juan Domingo Perón en los números finales de la revista. En un contexto caracterizado por el crecimiento de diversas luchas sociales contra la dictadura de Ongania, surgió en la revista entre los años 1968 y 1969 un sujeto revolucionario plural, que tenía en su centro a la clase obrera, pero que también incluía y buscaba articular a diferentes grupos considerados revolucionarios, como los cristianos y los estudiantes. En el nivel de los proyectos políticos, tal articulación de identidades y luchas suponía el surgimiento de una hegemonía alternativa, que según C \& R, no podía avanzar si no se conformaba una vanguardia armada. Esta situación, sin embargo, se modificó a principios de la década del setenta con dos hechos de gran importancia: la proliferación de acciones desarrolladas por las organizaciones armadas, y el retorno de Perón.

Precisamente, fue el paulatino incremento de las posibilidades de que se produjera aquel retorno lo que determinó una modificación del mapa de la lucha hegemónica, en el que el peronismo fue ocupando un lugar cada vez importante. Ante este panorama, la posición ideológica de C \& R comenzó a cambiar, alineándose cada vez más con la figura del exiliado líder. El sujeto revolucionario dejó de ser esa pluralidad de diversas identidades políticas revolucionarias, y su lugar fue ocupado por las organizaciones armadas y el propio Perón. Discursivamente, se lo buscó separar de los políticos burgueses, "traidores”, y asociarlo con el denominado "Ejercito Peronista". Pero toda esta operación terminó por herir de muerte al proyecto de hegemonía alternativa articulado por la revista. Ante el cada vez más probable retorno de las elecciones, pareció quedar en claro que no era suficiente con lo nuevo, con aquel proyecto, sino que era necesario recuperar una tradición que estaba en disputa, representada por el propio General. Lo emergente pasó a ocupar un papel residual, y la lucha hegemónica se fue institucionalizando.

Pero, ¿por qué ocurrió esto? Con esto llegamos a la conclusión del libro, en donde se ofrece una respuesta a la pregunta central de la investigación: si realmente surgió una hegemonía alternativa. Esteban Campos, basándose en las entrevistas realizadas a ex militantes de C \& R, llega a la conclusión de que, en el nivel de las prácticas concretas, esto nunca ocurrió. Había una clara diferencia entre el discurso de la revista y el campo de recepción. La mayoría de los militantes entrevistados afirman no haber pensado, durante aquellos años, en la posibilidad de construir una hegemonía que fuera más allá del propio Perón; que fuera por lo tanto verdaderamente "alternativa". Es esto lo que, en última instancia, permite entender el cambio en la línea editorial de la revista ante el cada vez más posible retorno del líder peronista, así como el hecho, más 
importante, de que el proyecto de hegemonía alternativa que alguna vez intentara articular terminara, incluso desde un punto de vista discursivo, naufragando. 